\title{
ANALISANDO OS RELACIONAMENTOS DAS FINANÇAS EMPRESARIAIS COM O EMPREENDEDORISMO SOCIAL, SUSTENTÁVEL E AMBIENTAL UTILIZANDO MAPAS BIBLIOMÉTRICOS
}

\author{
ANALYZING THE RELATIONSHIPS OF CORPORATE FINANCE WITH SOCIAL, \\ SUSTAINABLE AND ENVIRONMENTAL ENTREPRENEURSHIP USING \\ BIBLIOMETRIC MAPS
}

\author{
Itamir Caciatori Junior \\ PPGADM - Universidade Federal do Paraná - UFPR \\ itamircj@gmail.com \\ Rivanda Meira Teixeira \\ PPGADM - Universidade Federal do Paraná - UFPR \\ rivandateixeira@gmail.com
}

Submissão: 07/02/2020

Aprovação: 06/05/2021

\begin{abstract}
RESUMO
Os recursos financeiros são uma das principais fontes de sustentabilidade das empresas com objetivos sociais, sustentáveis e ambientais. Este estudo busca examinar as relações entre o empreendedorismo social, sustentável e ambiental com as finanças empresariais. Após levantamento de referências bibliográficas localizadas nas bases de dados Scopus e Web of Science foi realizada a análise dos dado

s com a utilização de mapas bibliométricos. A análise das distâncias de palavras-chave nos mapas bibliométricos demonstra que as finanças empresariais ainda são pouco exploradas na literatura desses três tipos de empreendedorismo. Foi constatado que os termos crowdfunding e financial performance são os que apresentam maior aderência com empreendedorismo sustentável em comparação com o social e o ambiental. As limitações encontradas referem-se à sobreposição de trabalhos resultantes das pesquisas bibliográficas de empreendedorismo sustentável e ambiental, além do reduzido tamanho dos mapas gerados por esses temas em conjunto com as finanças empresariais.
\end{abstract}

Palavras-chave: Finanças empresariais; Empreendedorismo social; Empreendedorismo sustentável; Empreendedorismo ambiental; Bibliometria.

\begin{abstract}
Financial resources are one of the primary sources of sustainability for companies with social, sustainable and environmental objectives. This study seeks to examine the relationships between social, sustainable and environmental entrepreneurship with business finance. After a survey of bibliographical references located in the Scopus and Web of Science databases, the data analysis was performed with the use of bibliometric maps. The keyword distances analysis in the bibliometric maps shows that business finance is still little explored in the literature of these three types of entrepreneurship. It has been found that the terms
\end{abstract}


crowdfunding and financial performance are those that present greater adherence to sustainable compared to social and environmental entrepreneurship. The limitations refer to the overlapping of work resulting from bibliographical research on sustainable and environmental entrepreneurship, as well as the small size of the maps generated by these themes in conjunction with business finance.

Keywords: Business finance; Social entrepreneurship; Sustainable entrepreneurship; environmental entrepreneurship; bibliometrics.

\section{INTRODUÇÃO}

Dentre os diferentes tipos de recursos que possibilitam o sucesso de empreendimentos, os recursos financeiros demandam atenção especial, uma vez que são uma das principais fontes de sustentabilidade das empresas. Dessa forma, independentemente de sua origem, motivação e finalidade, dificilmente uma organização terá capacidade de se manter de forma perene sem um tratamento adequado das suas finanças empresariais.

O presente estudo busca identificar as relações desses recursos financeiros com o empreendedorismo social, sustentável e ambiental, por meio de mapas bibliométricos. A escolha desses três tipos de empreendedorismo ocorreu em razão desses negócios declararem a extrapolação de seus objetivos além do lucro contábil e da riqueza econômica. Dessa forma, Dacin et al. (2010), Hall et al. (2010) e Gibbs (2009) argumentam que esses tipos de negócios incluem em sua missão e resultados elementos como a criação de valor social, criação de uma sociedade sustentável e voltada à solução de problemas ambientais.

O empreendedorismo social, na concepção de Mair; Martí (2006), é um conceito que pode ser visualizado de forma ampla como um processo que envolve o uso inovador e a combinação de recursos para buscar oportunidades de catalisar, mudar e/ou atender as necessidades sociais. Essa visão, segundo Dacin; Matear (2010), não exclui a necessidade de rendimentos, apenas aloca uma priorização diferenciada para o assunto e caracteriza o empreendedorismo social como um domínio distintivo do empreendedorismo.

Em uma ótica das oportunidades Shane; Venkataraman, (2000) afirmam que o empreendedorismo sustentável busca explicar como o empreendedorismo pode ajudar a resolver os problemas ambientais dos sistemas econômicos por meio da descoberta, avaliação e exploração de oportunidades presentes no mercado. Visto de forma ampla, Dean; Mcmullen (2007) incluem nessa categoria o empreendedorismo ambiental como uma de suas subcategorias.

Também classificado como empreendedorismo verde ou "green-entrepreneurship", o empreendedorismo ambiental, para Kirkwood; Walton (2010), está centrado nos ecoempreendedores, que iniciam negócios com fins lucrativos, fortes valores ambientais e vendem produtos ou serviços ambientais. Também composto por valores sociais, sua classificação está ligada às práticas ambientais e o desejo de tornar o mundo um lugar melhor para se viver. Gibbs (2009), vincula o empreendedorismo ambiental à modernização ecológica, como uma forma de superar as crises ambientais.

Este estudo pretendeu preencher lacuna teórica ao analisar de forma conjunta os aspectos financeiros na pesquisa sobre empreendedorismo social, sustentável e ambiental. Pesquisa anterior realizada nas bases de dados Scopus e Web of Science (WOB) identificou a existência de 13 estudos bibliométricos que tratam de Empreendedorismo Social, Sustentável e Ambiental.

Desses artigos, 12 tratam de Empreendedorismo Social e um trata de empreendedorismo sustentável em conjunto com o ambiental, porém, as finanças empresariais se mostraram um tema inexplorado nesse conjunto. 
A quantidade de bases de dados disponíveis para pesquisas bibliográficas apresentou um crescimento exponencial nos últimos anos, o que demanda, em conjunto com a citada lacuna, que o método bibliométrico fosse utilizado para possibilitar a organização e análise das buscas.

Em relação a escolha do método bibliométrico, Zupic; Čater (2015) ressaltam que os pesquisadores, em especial os estudantes de doutorado, devem estar equipados com habilidades adequadas devido à maior disponibilidade das informações surgidas recentemente. Esses métodos possibilitam o tratamento quantitativo, organização e representação dos assuntos por meio de mapas bibliométricos elaborados com uso de softwares específicos. Para este estudo foram realizadas nas bases de dados Scopus e Web of Science (WOS) e organizadas por meio do software Publish or Perish. O software VOSviewer foi utilizado para a construção dos mapas bibliométricos relacionando os termos encontrados. Esse trabalho pretende contribuir teoricamente com a identificação da inserção da dimensão das finanças empresariais na pesquisa do empreendedorismo social, sustentável e ambiental, identificando quais artigos apresentaram maior relevância no estudo das relações entre esses temas por meio da análise via mapas bibliométricos.

Como contribuição prática pretende identificar os problemas ligados às finanças empresariais nesses três campos de empreendedorismo. Isso decorre do fato de que, não obstante as preocupações desses campos sejam genuínas, questões financeiras e de funding podem afetar os objetivos e o andamento de iniciativas nos campos social, sustentável e ambiental.

A estrutura do artigo inicia-se com a revisão da literatura dos três tipos de empreendedorismo e de suas relações com as finanças. A seguir aborda as principais técnicas bibliométricas, seguido pelos resultados da pesquisa. Por último, são descritas as considerações finais e as sugestões para pesquisas futuras.

\section{REVISÃO DE LITERATURA}

\subsection{EMPREENDEDORISMO SOCIAL E FINANÇAS EMPRESARIAIS}

A sustentabilidade financeira é uma das principais preocupações dos empreendedores sociais e as estratégias mistas de financiamento podem propiciar o crescimento orgânico das empresas sociais e direcionar seus impactos (MARTIN, 2015).

As estruturas de financiamento dos negócios do empreendedorismo social, na visão de Achleitner; Spiess-Knafl; Volk (2014), possuem uma estrutura de fluxo de caixa concentrada, ao contrário das empresas tradicionais. Ressaltam que isso se deve aos conflitos quanto à origem do capital e dos investidores interessados no negócio. Para evitar isso, os autores sugerem que as empresas sociais devem adaptar suas expectativas com as dos seus financiadores (capitalistas) e alinhar suas estratégias de acordo com esses requisitos.

Os conflitos e as tensões entre os objetivos financeiros e sociais das empresas sociais também foram analisados por Siegner; Pinske; Panwar (2018) que discutem que, ao contrário de enfrentar ou dividir esses objetivos, as empresas sociais optam por conviver com essas tensões ao invés de enfrentá-las. Uma das origens desses conflitos está nas divergências dos interesses das partes. Inicialmente, os capitalistas podem não estar inicialmente interessados nos objetivos sociais do empreendedor, mas sim na natureza disruptiva do conceito do negócio analisado (HARJULA, 2005).

A busca de recursos financeiros pelos mecanismos tradicionais, como as instituições financeiras, foi destacado por (CALIC; MOSAKOWSKI, 2016). Ressaltam que essa lacuna pode ser preenchida pela forma inovadora pelo crowdfunding (financiamento coletivo). Sugerem que a legitimação do projeto e a criatividade dos empreendedores sociais atuam como mediadores entre a orientação sustentável e o sucesso na obtenção de recursos 
financeiros. O crowdfunding também foi citado por Bergamini; Navarro; Hilliard, 2017) e Bernardino; Santos (2016) como uma opção de financiamento para essas empresas. Por meio de estudos de caso, analisaram percepções sociais dessa forma de financiamento como fonte de recursos para os empreendedores sociais. Porém, concluíram que o crowdfunding é desconhecido e pouco usado entre os empreendedores sociais.

Para Brown; Boon; Pitt (2017) essa forma de financiamento permite a obtenção de investimentos que não seriam recebidos de outras formas tradicionais, como bancos, investidores-anjo ou mercado de capitais. Além disso, os autores acrescentam que um grande número de startups possui origens no crowdfunding.

O crowdfunding foi descrito por Lehner (2013) sob oito óticas diferentes: tipos e funções de utilidade; governança corporativa; relações com investidores; reporte e risco; reconhecimento de oportunidades; redes de trabalho; métricas financeiras e; obstáculos regulatórios. Utilizando análise de empresas libanesas, Kallab; Salloum (2017) verificaram que o acompanhamento acadêmico, treinamento e apoio financeiro afetam positivamente o desempenho das empresas de empreendedorismo social e, consequentemente, a criação de empregos. Para Brandstetter; Lehner (2015), portfólios de investimentos podem contemplar as empresas sociais como forma de mitigar riscos da carteira e contribuir para a sustentabilidade.

Uma nova forma de obtenção de recursos financeiros também pode ser via capitalistas de risco social, por meio de entrevistas com investidores (MILLER; WESLEY, 2010). Os autores verificaram que nem todos os investidores estudados analisam empreendimentos sociais da mesma forma, sendo influenciados por investimentos sociais específicos.

As divergências e conflitos de interesses na obtenção de recursos financeiros podem estar relacionados às diferenças entre as estruturas de capital das empresas sociais e aquelas concebidas com fins comerciais (SIQUEIRA et al., 2018; NICHOLLS, 2010). Este último argumenta que existem diferentes lógicas de investimentos e racionalidades nos investimentos em empresas sociais.

\subsection{EMPREENDEDORISMO SUSTENTÁVEL E FINANÇAS EMPRESARIAIS}

Assim como ocorre nos demais empreendimentos, as crises econômicas possuem grandes impactos em empresas sustentáveis. Utilizando como exemplo a crise de 2008, Kraus et al. (2018) afirmaram que os investimentos nesse tipo de empresas foram reduzidos, mesmo em comparação com o aporte de recursos em organizações tradicionais com a finalidade de lucro econômico.

Apesar de o crowdfunding ser uma ferramenta alternativa para a captação de recursos para as empresas sustentáveis, Hörisch (2015) demonstrou que a orientação sustentável dos projetos apresentados para financiamento não pode ser relacionada com o sucesso das campanhas analisadas, o que demonstra, segundo o autor, ineficiência do apelo sustentável das empresas demandantes de financiamento coletivo.

Utilizando metodologia semelhante para análise dessa modalidade de crédito, Hörisch (2018) verificou os projetos que não possuem objetivos de grande crescimento no mercado são aqueles que obtém maiores taxas de sucesso nos objetivos utilizando essa forma de financiamento. A opinião pública e o impacto da marca foram descritos como Chen et al. (2018) como os dois fatores que apresentam maior impacto no sucesso de financiamento por esse tipo de plataforma.

Além dos recursos financeiros propiciados pelos investidores, estes também podem fornecer aconselhamentos e redes de contatos para as empresas sustentáveis (BOCKEN, 2015). O autor também demonstra como os investidores analisam as funções, motivações, 
barreiras, fatores de sucesso, teses de investimento e papeis dos negócios sustentáveis no processo de decisão de investimentos.

A confiança na perenidade e na possibilidade de longa duração das empresas iniciantes, principalmente as startups, conforme destacado por Lange (2017), são fatores fundamentais para se obter o apoio dos investidores. Apesar disso, o autor constatou que os investidores evitam empresas sustentáveis, principalmente aquelas que demonstram preocupação de sustentabilidade ambiental.

Apesar das preocupações dos investidores quanto ao potencial risco elevado desse tipo de empresas, o que torna mais difícil a captação de recursos financeiros em comparação com as empresas tradicionais, Hoogendoorn; van der Zwan; Thurik (2017) concluíram que não existem diferenças significativas entre a percepção quanto aos riscos financeiros por esses dois tipos de empreendedores.

Outra forma de obtenção de recursos financeiros pode ocorrer com o excedente gerado por uma empresa tradicional lucrativa, denominada âncora. Nesse aspecto, Wheeler et al. (2005) analisaram empresas sustentáveis que obtiveram sucesso e desenvolveram um modelo conceitual denominado Modelo Local de Redes de Empresas Sustentáveis. Essa empresa paralela pode ser uma cooperativa com a finalidade de lucro econômico, por exemplo.

A dispersão dos benefícios gerados por empresas sustentáveis, aliados à necessidade de capital intensivo, grandes riscos associados às novas tecnologias e fortes barreiras à saída, foram citados por (Cumming; Henriques; Sadorsky (2016) como fatores que tornam difícil o financiamento de inovações sustentáveis. Apesar da dificuldade de avaliação, os benefícios são capturados pelos investidores e pela sociedade por meio da redução na degradação ambiental, melhora nos índices de saúde pública e aumento no padrão de qualidade de vida. Outros elementos facilitadores para obtenção de recursos financeiros podem assegurar a viabilidade financeira de Pequenas e Médias Empresas (PMEs). No caso das certificações ambientais, Djupdal (2014) verificou que apenas aquelas PMEs com alta adequação a essas certificações ambientais obtiveram melhoria em seu desempenho financeiro.

\subsection{EMPREENDEDORISMO AMBIENTAL E FINANÇAS EMPRESARIAIS}

A necessidade de não se concentrar apenas nas formas habituais de crédito bancário e de se utilizar mecanismos inovadores de financiamentos para o empreendedorismo ambiental foi abordada por Randjelovic; O'rourke; Orsato (2003). Os autores descreveram o papel do capital "verde" e forneceram uma visão geral do mercado para esse tipo de negócio, que tem como principais dificuldades: falta de uma rede de contatos própria; diferentes significados para sustentabilidade e ambiente; ausência de um bom plano de negócios; estágio da empresa (timing); baixo grau de experiência e de habilidades de ambas as partes (financiadores e empreendedores) e; desconhecimento das perspectivas no mercado.

Os fatores que geram mais motivação nos investidores, segundo Koellner; Sell; Navarro (2010), são os objetivos financeiros dos empreendedores e as origens das empresas. Os autores analisaram os esquemas de pagamentos por serviços relacionados ao ecossistema, que apresentam crescimento em países tropicais, bem como as expectativas dos investidores dispostos a empregar seu capital nessas atividades. Esses financiadores também podem ser microinvestidores, (ESTAPÉ-DUBREUIL; ASHTA; HÉDOU, 2016).

Fatores econômicos, como a assimetria de informações e o baixo percentual de garantias oferecidas na concessão dos créditos, foram descritos por Demirel et al. (2017) como as principais barreiras ao investimento na área do empreendedorismo ambiental. Outros fatores de destaque são a incerteza e complexidade das tecnologias envolvidas, inabilidade dos investidores externos em identificar o estágio de ciclo de vida das empresas, falta de 
sinais específicos (como patentes de produtos ambientais ou produtos associados ao conceito) e a discriminação existente nos bancos para esses financiamentos.

Quanto à diferenciação na obtenção de recursos financeiros entre as empresas com finalidade ambiental e as empresas tradicionais, em específico as empresas de alta tecnologia, Mrkajic; Murtinu; Scalera (2017), apontam aquelas com clara definição dos objetivos ambientais que não estão mais propensas a obter financiamentos externos em comparação com outros tipos de empresas de alta tecnologia.

\subsection{CONTRIBUÇÕES DAS FINANÇAS EMPRESARIAIS NOS ESTUDOS DE EMPREENDEDORISMO SOCIAL, SUSTENTÁVEL E AMBIENTAL}

Ao se analisar a influência das finanças empresariais nos estudos realizados em cada uma das dimensões de empreendedorismo apresentadas anteriormente, pode-se constatar que as finanças interferem de formas variadas nas decisões de criação de novos negócios assim como em todo o processo empreendedor.

No caso do empreendedorismo social as finanças empresariais foram identificadas no estudo de Achleitner; Spiess-Knafl; Volk (2014) que analisa o conflito entre o foco social e o foco econômico do negócio. Essa dicotomia entre lucro e o objetivo social também tem sido objeto de debates entre autores como SIEGNER; PINSKE; PANWAR (2018).

Outro aspecto essencial na criação de negócios com foco social é a busca de recursos financeiros para a sua sobrevivência, a exemplo de estudos sobre Crowfunding, como os de BERGAMINI; NAVARRO; HILLIARD, (2017) E BERNARDINO; SANTOS (2016)

Por sua vez, para a criação de negócios sustentáveis a dificuldade de conseguir investidores é destacada nos estudos de Kraus et al. (2018) e Hörisch (2015) e Lange (2017). Wheeler et al. (2005) também destacam a criação e manutenção de empresas-âncora para auferir lucros financeiro e, consequentemente, manter os empreendimentos de caráter sustentável.

Finalmente, para a criação de negócios com foco ambiental, o capital "verde" é descrito por autores como RANDJELOVIC; O'ROURKE; ORSATO (2003) e DEMIREL ET AL. (2017). Estes últimos autores descrevem barreiras ao investimento em iniciativas de empreendedorismo ambiental, notadamente questões ligadas ao ciclo de vida das empresas e tratamento dos bancos a esses agentes.

\section{METODOLOGIA}

A bibliometria, com a utilização de mapas bibliométricos, foi a metodologia adotada para o presente trabalho, mais especificamente para a identificação das relações entre as finanças empresariais e os campos do empreendedorismo social, sustentável e ambiental.

Classificada como uma ciência acadêmica por Gutiérrez-Salcedo et al. (2018), a bibliometria tem como principal objetivo avaliar a pesquisa desenvolvida por uma comunidade científica nos campos da ciência. Para isso, utiliza-se de um conjunto de métodos para estudar ou medir a ciência por meio de publicações científicas armazenadas ou indexadas em grandes bases bibliográficas. O principal propósito da bibliometria é melhorar a documentação, informação e comunicação científica pela análise quantitativa das coleções de obras e serviços (OSAREH, 1996). Assim, enquanto contribui para um melhor entendimento do mecanismo de pesquisa científica como uma atividade social, a análise quantitativa da geração, propagação e utilização de aspectos da informação científica é feita de acordo com técnicas de Cientometria. 
Dessa forma, os métodos bibliométricos, conforme ressaltado por Zupic; Čater (2015), permitem que os pesquisadores baseiem suas buscas em dados bibliográficos agregados produzidos por outros cientistas. A análise agregada desses dados possibilita reflexões sobre a estrutura, redes de pesquisa e tópicos de interesse no campo de pesquisa estudado. Os autores alertam que esses métodos não são um substituto para os métodos de pesquisa tradicionais, apenas uma forma diferenciada de se analisar a estrutura do campo de pesquisa.

A análise de desempenho das publicações e o mapeamento da ciência são os dois métodos principais descritos por Gutiérrez-Salcedo et al. (2018) para explorar um campo de pesquisa. O primeiro está relacionado com o impacto das citações das produções científicas de diferentes autores, relacionadas com as citações recebidas ou fator de impacto dos periódicos utilizados para publicação. O segundo, mapeamento da ciência, busca demonstrar a estrutura do campo de pesquisa, sua evolução e seus aspectos dinâmicos via análise das redes de colaboração entre autores, conceituais e de publicações citadas. Os autores formularam uma sequência de cinco técnicas para demonstrar as relações entre os trabalhos, autores, periódicos e palavras-chave, conforme descrito na Figura 1Erro! Fonte de referência não encontrada..

\begin{tabular}{ll}
\hline Técnica & Descrição \\
\hline Análise de citações & $\begin{array}{l}\text { Demonstra os trabalhos, autores ou periódicos mais citados } \\
\text { Demonstra a frequência em que dois autores são citados no } \\
\text { mesmo trabalho }\end{array}$ \\
Análise de co-citações & $\begin{array}{l}\text { Utiliza a quantidade de referências compartilhadas por dois } \\
\text { documentos para construir medidas de similaridade entre eles }\end{array}$ \\
Análise de co-autores & $\begin{array}{l}\text { Examina as redes sociais de cientistas para colaboração em } \\
\text { artigos científicos } \\
\text { Análiza }\end{array}$ \\
relacionamentos
\end{tabular}

Figura 1 - Resumo de métodos bibliométricos

Fonte: Adaptado de Zupic, I., \& Čater, T. (2015). Bibliometric Methods in Management and Organization (p 432). Organizational Research Methods, 18(3), 429-472.

\subsection{ETAPAS DA PESQUISA}

Para a realização desse estudo, foram adotadas as cinco etapas sugeridas por Zupic; Čater (2015), descritas sequencialmente na Figura 2:

\begin{tabular}{|c|c|}
\hline Etapa & Atividades \\
\hline Projeto de pesquisa & $\begin{array}{l}\text { Definição da pergunta de pesquisa } \\
\text { Escolha do método bibliográfico mais adequado para a pergunta de } \\
\text { pesquisa }\end{array}$ \\
\hline $\begin{array}{l}\text { Compilação dos dados } \\
\text { bibliométricos }\end{array}$ & $\begin{array}{l}\text { Construção da base de dados com referências obtidas das bases } \\
\text { Scopus e ISI - Web of Science } \\
\text { Filtragem e exportação dos dados bibliográficos }\end{array}$ \\
\hline Análise & $\begin{array}{l}\text { Escolha dos softwares bibliométricos à Publish or Perish } \\
\text { Limpeza e pré-processamento dos dados }\end{array}$ \\
\hline Visualização & $\begin{array}{l}\text { Escolha do método de visualização à Análise de redes } \\
\text { Seleção do software para visualização dos resultados (VOSviewer) }\end{array}$ \\
\hline \multicolumn{2}{|c|}{ Interpretação dos resultados } \\
\hline \multicolumn{2}{|c|}{$\begin{array}{l}\text { Figura } 2 \text { - Etapas da pesquisa bibliométrica } \\
\text { Fonte: Adaptado de Zupic, I., \& Čater, T. (2015). Bibliometric Methods in Mar }\end{array}$} \\
\hline
\end{tabular}


Organization (p 432). Organizational Research Methods, 18(3), 429-472.

A escolha do método bibliométrico, como recomendado por Zupic; Čater (2015), deve ser aderente com a pergunta de pesquisa escolhida. Assim, técnicas como análise de citações, co-citações ou acoplamento bibliográfico devem corresponder aos resultados que os pesquisadores querem efetivamente analisar em suas perguntas de pesquisa. Para o presente trabalho, a pergunta central de pesquisa foi: Como as finanças empresariais são abordadas na literatura acadêmica do empreendedorismo social, sustentável e ambiental?

A segunda etapa da pesquisa iniciou com a definição das palavras-chave relacionadas ao assunto. Essas escolhas partiram da análise de palavras relacionadas em artigos da área, como o de Klewitz; Hansen (2014). As pesquisas para identificação as palavras-chave partiu dos termos utilizados em artigos relacionados às três áreas do empreendedorismo e em publicações de finanças. Com base nos termos iniciais, foram realizadas pesquisas por sinônimos nos aplicativos Wordtracker e Wordstream, os quais permitem a identificação de buscas realizadas com termos semelhantes na internet. A relação final das palavras-chave termos pode ser visualizada na Figura 3.

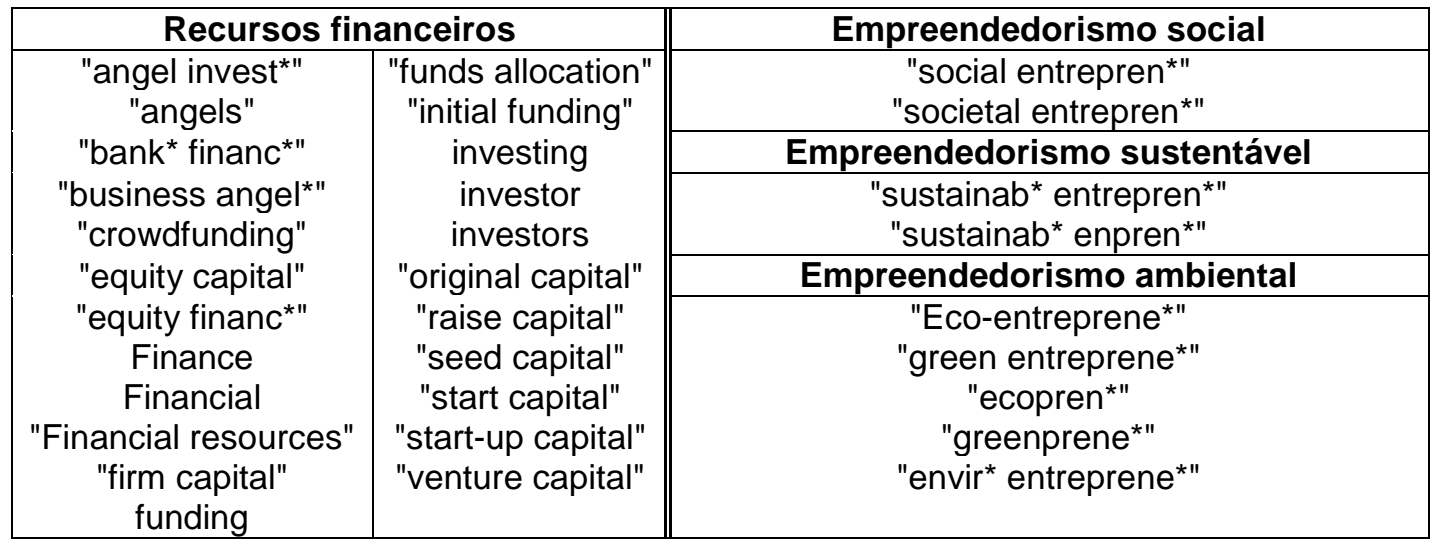

Figura 3 - Palavras-chave utilizadas nas pesquisas

Fonte: Elaborado pelos autores, 2020

Com base nessas palavras, foram realizadas buscas nas bases Scopus e ISI - Web of Science, inicialmente apenas pelos termos isolados e, em uma segunda etapa, em conjunto com os termos de finanças (função "AND”). Os tipos de documentos pesquisados foram artigos de periódicos, artigos de congressos, livros e capítulos de livros. Optou-se pela ampliação além dos periódicos para contemplar uma maior quantidade de trabalhos relacionados aos temas. Essas pesquisas resultaram nas quantidades exibidas na Tabela 1.

Tabela 1

Tipos de Empreendedorismo e participação dos trabalhos relacionados às finanças

\begin{tabular}{|c|c|c|c|c|c|c|c|}
\hline Quantidades e percentuais & 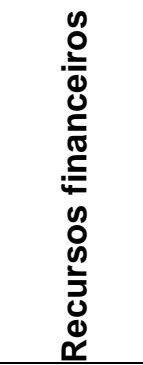 & 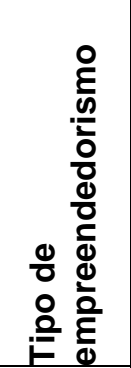 & 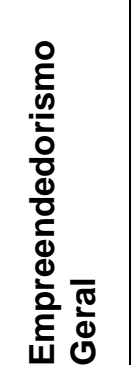 &  & 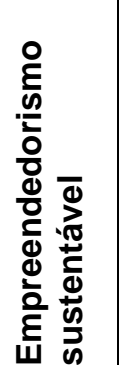 & 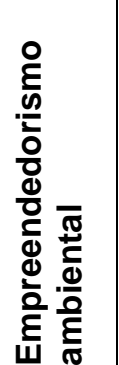 & 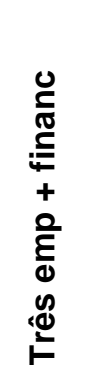 \\
\hline Scopus (total do termo) & 543.458 & 50.816 & 50.816 & 1.552 & 229 & 230 & 1.966 \\
\hline Scopus + financeiro & - & 8.706 & 8.706 & 276 & 38 & 32 & 346 \\
\hline $\begin{array}{l}\text { \% financeiro com } \\
\text { empreendedorismo }\end{array}$ & - & $17 \%$ & $17 \%$ & $18 \%$ & $17 \%$ & $14 \%$ & $18 \%$ \\
\hline Qtde WOS (total dos termos) & 253.727 & 37.542 & 37.542 & 1.361 & 285 & 181 & 1.739 \\
\hline WOS + financeiro & - & 7.956 & 7.956 & 277 & 62 & 34 & 363 \\
\hline
\end{tabular}




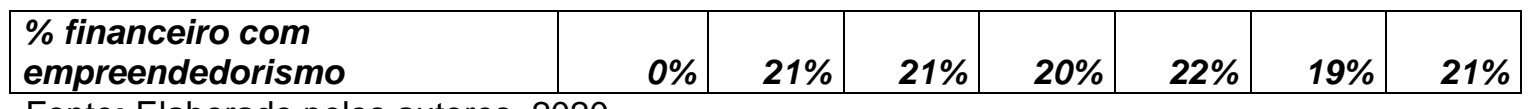

Fonte: Elaborado pelos autores, 2020

Os resultados das pesquisas geraram 50 arquivos nos formatos RIS (Information Systems Research), TXT (texto) e CSV (Comma Separated Values), utilizados posteriormente na elaboração dos mapas bibliométricos. Ressalte-se que também foram geradas as referências utilizadas nos trabalhos pesquisados, informações necessárias para a posterior criação de redes de acoplamento bibliográfico.

A terceira etapa, a análise, consistiu na eliminação de duplicidades geradas pelas buscas nas duas bases de dados, correção de dados inválidos, preenchimento de campos em branco e elaboração de arquivos únicos utilizando o software Publish or Perish (PoP), elaborado para gerenciamento de referências bibliográficas. O PoP permite a busca em diferentes bases de dados (Scopus, Web of Science, Google Scholar e Microsoft Academic), além de permitir a importação de arquivos de citação externos (formatos *.csv, *.ris e *.txt, por exemplo).

A visualização, quarta etapa sugerida por Zupic; Čater (2015), foi realizada a partir da construção dos mapas bibliométricos, realizada com o software VOSviewer. O programa, idealizado por (van eck; WALTMAN, 2010), permite a visualização gráfica das referências nos níveis de rótulos, densidade, cluster e dispersão, utilizando um algoritmo que permite as visualizações sem sobreposição para não prejudicar o entendimento. O software também possibilita atribuir pesos para os trabalhos mais citados e ligações entre as publicações.

A técnica utilizada na construção dos mapas considera a distância entre os itens, obtida a partir do escalonamento multidimensional. Assim, quanto mais os itens aparecerem citados em conjunto, mais forte a relação entre eles e mais próximos eles estarão posicionados entre si. O tamanho dos itens demonstra graficamente a quantidade de citações que os itens recebem individualmente. Assim, quanto mais citados foram os itens (trabalhos, autores, revistas, etc.), maiores os tamanhos dos círculos em que eles estão inseridos. A construção dos mapas é realizada a partir de matrizes de similaridade e co-ocorrência, com posterior translação, rotação e espelhamento dos resultados gráficos obtidos. A seguir serão apresentados os resultados das relações entre as finanças empresariais e os três tipos de empreendedorismo, o social, o sustentável e o ambiental.

\section{RESULTADOS}

\subsection{EMPREENDEDORISMO SOCIAL E FINANÇAS EMPRESARIAIS}

Dentre as opções disponíveis para apresentação visual de forma consistente dos resultados e demonstração das relações entre o empreendedorismo social e as finanças empresariais, o método mais adequado foi a geração de um mapa bibliométrico com uso das palavras-chave dos artigos, demonstrado na Figura 4: 


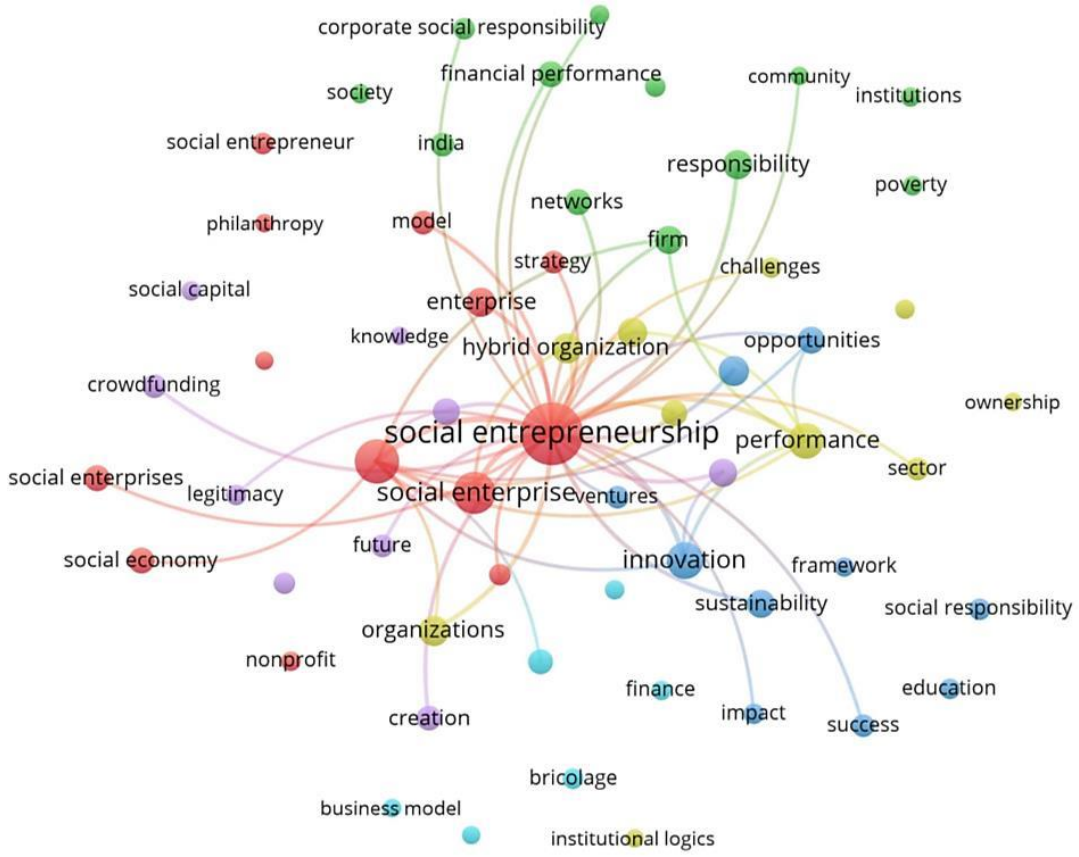

Figura 4 - Relação de palavras-chave entre empreendedorismo social e finanças Fonte: Elaborado pelos autores, 2020

Os resultados apresentados na Erro! Fonte de referência não encontrada., gerados pela associação entre as palavras-chave de 435 artigos, demonstram fraca associação entre os termos relacionados diretamente ao empreendedorismo social e as finanças das empresas, como "financial performance" (13 ocorrências - parte superior), "crowdfunding" (10 esquerda), "finance" (6 - parte inferior) e o termo "social entrepreneurship" (153 - centro).

Com relação aos termos financeiros, localizados na parte superior da figura, apresentaram maior associação com palavras não relacionadas diretamente ao empreendedorismo social, tais como "corporate social responsability" (8), "society" (6) e "community" (5), localizadas na parte superior da figura 1.

Por sua vez, as tentativas adicionais de construção de mapas bibliométricos a partir das citações das relações entre os artigos ou autores não apresentou formas de visualização que permitam conclusões sobre os relacionamentos.

Considerando as cinco principais publicações mais citadas obtidas do cruzamento entre os campos das finanças e do empreendedorismo social, verificou-se que apenas um dos trabalhos, Nicholls (2009) possui como foco as finanças empresariais, conforme descrito na Tabela 2:

Tabela 2

Trabalhos mais citados: empreendedorismo social e finanças empresariais

\begin{tabular}{lllc}
\hline Autor (ano) & Título & Periódico / Livro & $\begin{array}{l}\text { Quantidade } \\
\text { de citações }\end{array}$ \\
\hline $\begin{array}{lll}\text { J. Mair, I. } \\
\text { Marti (2006) }\end{array}$ & $\begin{array}{l}\text { Social entrepreneurship research: A } \\
\text { source of explanation, prediction, and } \\
\text { delight }\end{array}$ & $\begin{array}{l}\text { Journal of World } \\
\text { Business }\end{array}$ & 1797 \\
JC Short et al. & $\begin{array}{l}\text { Research in social entrepreneurship: } \\
\text { past contributions and future }\end{array}$ & $\begin{array}{l}\text { Strategic } \\
\text { Entrepreneurship }\end{array}$ & 352 \\
A. Fowler & $\begin{array}{l}\text { opportunities } \\
\text { NGDOS as a moment in history: }\end{array}$ & $\begin{array}{l}\text { Journal } \\
\text { Third World }\end{array}$ & 309 \\
A Nicholls & Beyond aid to social entrepreneurship & Quarterly \\
(2009) & $\begin{array}{l}\text { 'We do good things, don't we?': } \\
\text { 'Blended Value Accounting' in social }\end{array}$ & $\begin{array}{l}\text { Accounting } \\
\text { Organizations and } \\
\text { Society }\end{array}$ & 261
\end{tabular}




\begin{tabular}{lll}
$\begin{array}{l}\text { W. Drayton } \\
\text { (2002) }\end{array}$ & $\begin{array}{l}\text { The citizen sector: Becoming as } \\
\text { entrepreneurial and competitive as } \\
\text { business }\end{array}$ & $\begin{array}{l}\text { California } \\
\text { Management } \\
\text { Review }\end{array}$ \\
\hline
\end{tabular}

Fonte: Elaborado pelos autores, 2020

Os quatro artigos restantes tratam de aspectos gerais do empreendedorismo social, sem ligação direta com os aspectos financeiros das empresas.

\subsection{EMPREENDEDORISMO SUSTENTÁVEL E FINANÇAS EMPRESARIAIS}

O empreendedorismo sustentável apresentou, após a eliminação de duplicidades, 79 artigos em comum com o tema finanças empresariais. Nessa categoria, como ocorreu com o empreendedorismo social, a forma de apresentação visual mais adequada para demonstrar as relações entre o empreendedorismo sustentável e as finanças empresariais foi a construção de um mapa bibliométrico com agrupamento por palavras-chave, conforme demonstrado na Figura 5:

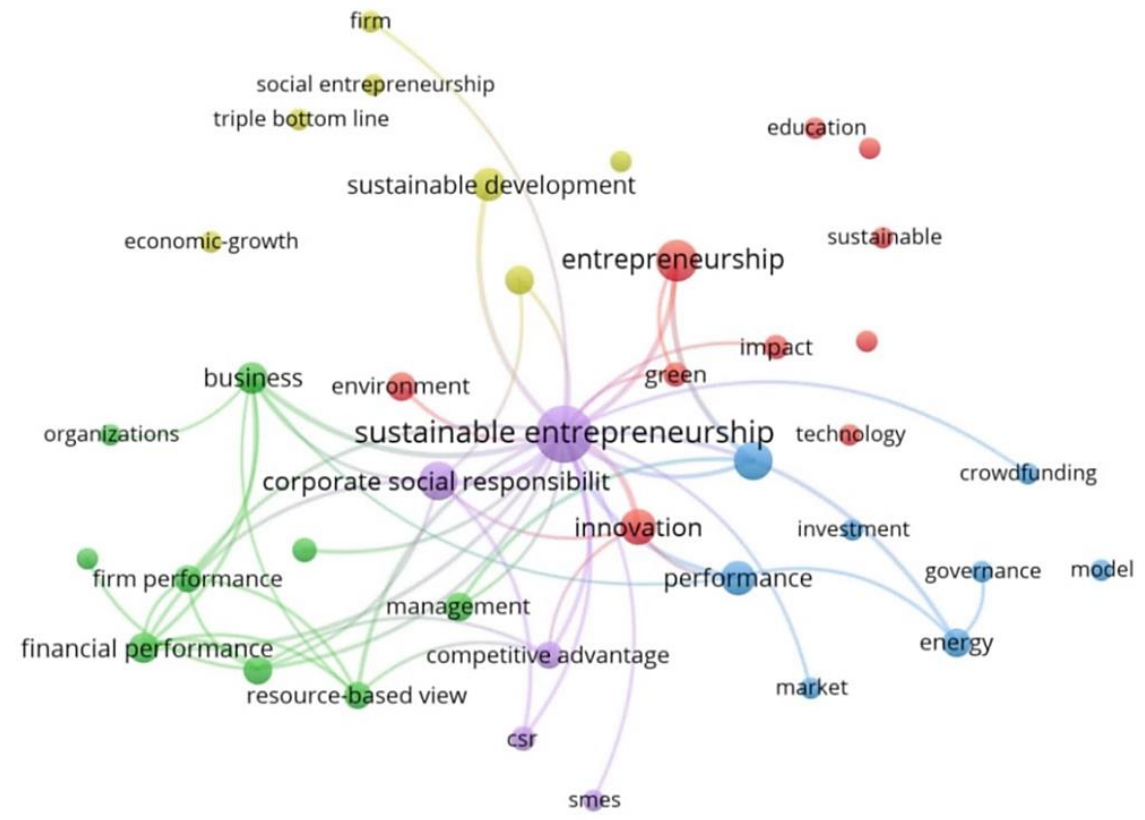

Figura 5 - Relação de palavras-chave entre empreendedorismo sustentável e finanças Fonte: Elaborado pelos autores, 2020

Observa-se no canto esquerdo inferior da Figura 5 um cluster (verde) composto por termos relacionados a "financial performance" (7), "resource-based view" (5) e "business performance" (6). Esse agrupamento, que reúne fatores relacionados ao desempenho das empresas, foi alocado de acordo com o algoritmo do software VOSviewer. Apesar disso, a distância do termo "financial performance" para o termo "sustainable entrepreneurship" (38) é relativamente grande, o que demonstra a baixa associação entre os dois termos para os artigos citados em conjunto.

Os termos "crowdfunding" (3) e "investment" (3), localizados em um cluster distinto à direita do mapa (azul), também demonstram considerável distância, sendo o tópico "investment" aquele que demonstra maior proximidade com a expressão "sustainable entrepreneurship".

$\mathrm{Na}$ análise dos arquivos de citações extraídos nas bases de dados, verificou-se que as pesquisas sobre empreendedorismo sustentável e empreendedorismo ambiental apresentaram alto grau de sobreposição das publicações analisadas. Dos 77 artigos selecionados para composição das análises entre empreendedorismo sustentável e finanças empresariais, 14 estavam mais relacionados com o empreendedorismo ambiental. Em alguns casos, por 
exemplo, verifica-se a ocorrência do problema por palavras chave, com a ocorrência do termo "sustentabilidade" em conjunto com "empreendedorismo ambiental". Com relação aos artigos mais citados na relação do empreendedorismo sustentável com as finanças empresariais, os resultados foram demonstrados na Figura 6:

\begin{tabular}{|c|c|c|c|}
\hline Autor (ano) & Título & Periódico / Livro & $\begin{array}{l}\text { Quantidade } \\
\text { de citações }\end{array}$ \\
\hline $\begin{array}{l}\text { AA Marcus, } \\
\text { AR Fremeth } \\
\text { (2009) }\end{array}$ & $\begin{array}{l}\text { Green Management Matters } \\
\text { Regardless }\end{array}$ & $\begin{array}{l}\text { Academy of Management } \\
\text { Perspectives }\end{array}$ & 143 \\
\hline $\begin{array}{l}\text { C. Rodgers } \\
(2010)\end{array}$ & $\begin{array}{l}\text { Sustainable entrepreneurship in SMEs: } \\
\text { A case study analysis }\end{array}$ & $\begin{array}{l}\text { Corporate Social } \\
\text { Responsibility and } \\
\text { Environmental } \\
\text { Management }\end{array}$ & 105 \\
\hline $\begin{array}{l}\text { B. Cohen et } \\
\text { al. }(2008)\end{array}$ & $\begin{array}{l}\text { Toward a sustainable conceptualization } \\
\text { of dependent variables in } \\
\text { entrepreneurship research }\end{array}$ & $\begin{array}{l}\text { Business Strategy and the } \\
\text { Environment }\end{array}$ & 79 \\
\hline $\begin{array}{l}\text { D. Wheeler et } \\
\text { al. (2005) }\end{array}$ & $\begin{array}{l}\text { Creating sustainable local enterprise } \\
\text { networks }\end{array}$ & $\begin{array}{l}\text { MIT Sloan Management } \\
\text { Review }\end{array}$ & 78 \\
\hline $\begin{array}{l}\text { N.M.P. } \\
\text { Bocken (2015) }\end{array}$ & $\begin{array}{l}\text { Sustainable venture capital - Catalyst } \\
\text { for sustainable start-up success? }\end{array}$ & $\begin{array}{l}\text { Journal of Cleaner } \\
\text { Production }\end{array}$ & 74 \\
\hline
\end{tabular}

Figura 6 - Trabalhos mais citados: empreendedorismo sustentável e finanças empresariais Fonte: Elaborado pelos autores, 2020

Dos cinco artigos com maior quantidade de citações dentre os 79 trabalhos filtrados nas áreas de empreendedorismo sustentável e finanças, apenas um (Bocken, 2015) possui orientação para a área de finanças, conforme demonstrado na Figura 6Erro! Fonte de referência não encontrada.. Os demais não apresentam foco na área financeira das organizações, e sim em aspectos gerais e pontuais do empreendedorismo sustentável.

\subsection{EMPREENDEDORISMO AMBIENTAL E FINANÇAS EMPRESARIAIS}

O cruzamento das bases de dados da Scopus e da Web of Science com o termo empreendedorismo ambiental e finanças gerou um total de 51 artigos. A Figura 7 demonstra o mapa bibliométrico segundo as palavras-chave das referências analisadas.

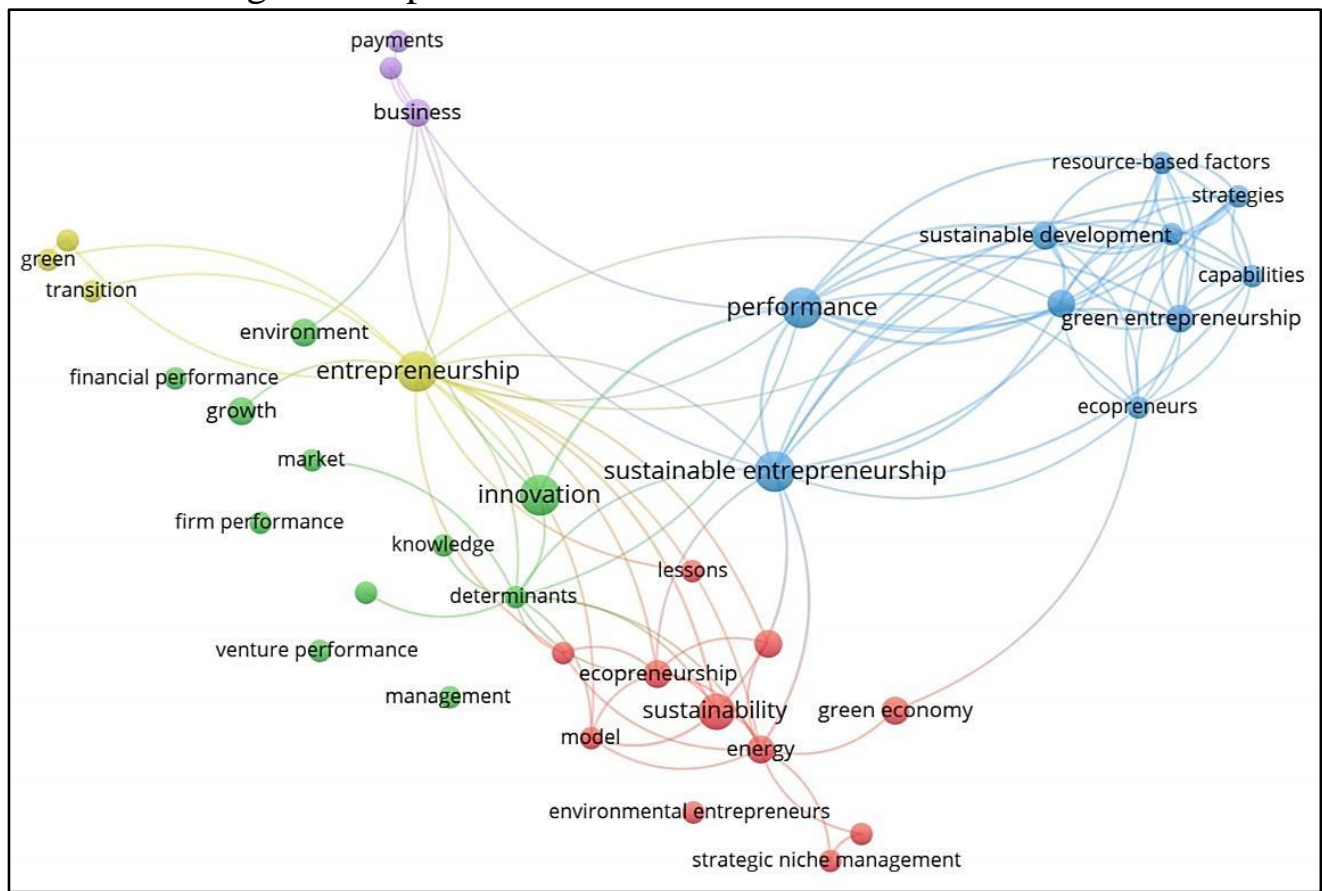

Figura 7 - Relação de palavras-chave entre empreendedorismo ambiental e finanças Fonte: Elaborado pelos autores, 2020 
Nesse mapa, o termo "financial performance" (2 - esquerda) foi o único relacionado às finanças empresariais. Ressalte-se que na Figura 7, em razão da quantidade reduzida de referências, esse termo teve um mínimo de duas repetições de palavras-chave para constar no mapa bibliométrico. O termo "crowdfunding", ao contrário do que ocorreu nas pesquisas anteriores, não constou no mapa porque não atingiu esse mínimo estipulado.

Destaca-se, também, o termo "sustainable entrepreneurship" com a maior quantidade de ocorrências (6). Assim, ao invés de as pesquisas terem como objetivo buscar trabalhos relacionados ao empreendedorismo ambiental, sinônimos como "green entrepreneurship"(3), "ecopreneurship"(3), "green business"(3) e "ecopreneurs"(2) surgiram em diferentes locais do mapa, demonstrando falta de unicidade no conceito de empreendedorismo ambiental.

Dentre os cinco artigos com maior quantidade de citações, todos foram relacionados também na área de empreendedorismo sustentável, conforme demonstrado na Figura 8Erro! Fonte de referência não encontrada.:

\begin{tabular}{|c|c|c|c|}
\hline Autor (ano) & Título & Periódico / Livro & $\begin{array}{l}\text { Quantidade } \\
\text { de citações }\end{array}$ \\
\hline $\begin{array}{l}\text { AA Marcus, AR } \\
\text { Fremeth (2009) }\end{array}$ & Green Management Matters Regardless & $\begin{array}{l}\text { Academy of Management } \\
\text { Perspectives }\end{array}$ & 171 \\
\hline $\begin{array}{l}\text { C. Rodgers } \\
(2010)\end{array}$ & $\begin{array}{l}\text { Sustainable entrepreneurship in SMEs: A } \\
\text { case study analysis }\end{array}$ & $\begin{array}{l}\text { Corporate Social } \\
\text { Responsibility and } \\
\text { Environmental } \\
\text { Management }\end{array}$ & 105 \\
\hline $\begin{array}{l}\text { B. Cohen et al. } \\
(2008)\end{array}$ & $\begin{array}{l}\text { Toward a sustainable conceptualization of } \\
\text { dependent variables in entrepreneurship } \\
\text { research }\end{array}$ & $\begin{array}{l}\text { Business Strategy and the } \\
\text { Environment }\end{array}$ & 88 \\
\hline $\begin{array}{l}\text { D. Wheeler et } \\
\text { al. (2005) }\end{array}$ & $\begin{array}{l}\text { Creating sustainable local enterprise } \\
\text { networks }\end{array}$ & $\begin{array}{l}\text { MIT Sloan Management } \\
\text { Review }\end{array}$ & 75 \\
\hline $\begin{array}{l}\text { N.M.P. Bocken } \\
(2015)\end{array}$ & $\begin{array}{l}\text { Sustainable venture capital - Catalyst for } \\
\text { sustainable start-up success? }\end{array}$ & $\begin{array}{l}\text { Journal of Cleaner } \\
\text { Production }\end{array}$ & 60 \\
\hline
\end{tabular}

Figura 8 - Trabalhos mais citados: empreendedorismo ambiental e finanças empresariais

Fonte: Elaborado pelos autores, 2020

Essa sobreposição confirma a eventual redundância de trabalhos na área que surgem a partir de pesquisas amplas, como é o caso do método bibliométrico. Assim como ocorreu no caso do empreendedorismo sustentável, torna-se difícil a análise individual dos mapas bibliométricos e das principais referências das duas áreas. Isso ocorre porque a repetição das referências que surgem a partir das pesquisas gera uma "área cinzenta".

\subsection{ANÁLISE CONJUNTA: EMPREENDEDORISMO SOCIAL, SUSTENTÁVEL E AMBIENTAL COM FINANÇAS EMPRESARIAIS}

Por último, os artigos de empreendedorismo social, sustentável e ambiental foram relacionados com os termos da área de finanças para apuração dos resultados. Essa forma de análise dos dados busca obter uma visão conjunta dos temas e verificar o possível surgimento de novas formas de relações. O primeiro mapa resultante foi o de co-citações, que demonstra a frequência com que dois artigos são citados no mesmo trabalho. A escolha por esse formato de co-citações ocorreu em razão das três redes formadas entre os artigos.

Para essa construção, exibida na Figura 9, foi estabelecido um mínimo de 10 citações de cada trabalho, o que resultou em três grupos diferentes. O grupo verde, localizado à esquerda, possui concentração nas áreas de empreendedorismo ambiental e empreendedorismo sustentável, sem traços que permitem identificar cada uma dessas duas categorias.

Os dois grupos restantes, em vermelho e azul, localizados respectivamente no lado direito e na parte inferior, apresentam trabalhos relacionados ao empreendedorismo social. 
Apesar disso, o grupo azul também contém artigos mais aderentes com aspectos gerais do empreendedorismo e outras áreas, como, por exemplo, os de Shane; Venkataraman (2000) e Schumpeter (1983).

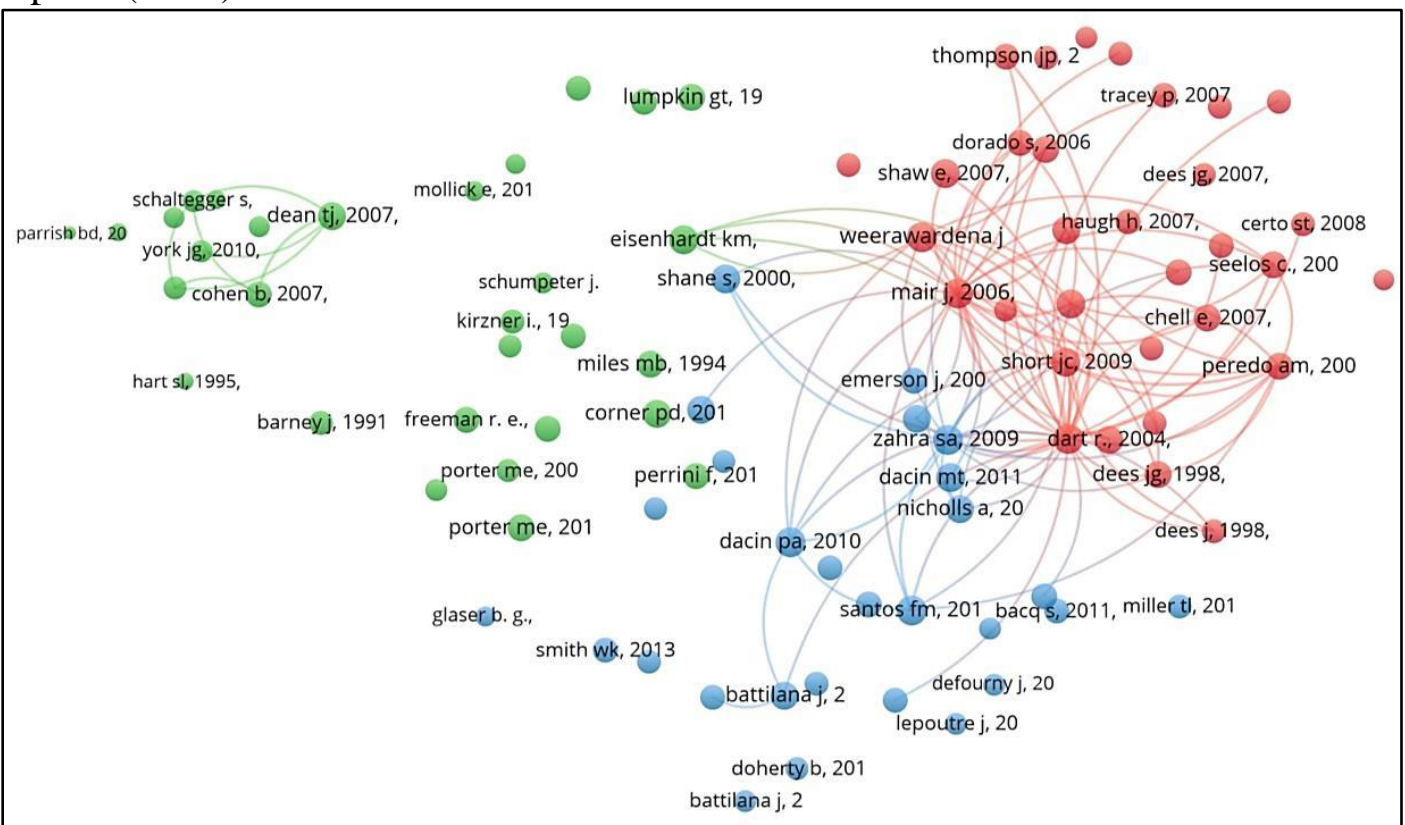

Figura 9 - Mapa de co-citações entre os três tipos de empreendedorismo e as finanças Fonte: Elaborado pelos autores, 2020

Os trabalhos relacionados às finanças empresariais não apresentaram destaque na Figura 9. Por se tratar de um mapa de co-citações, pode-se denotar que trabalhos nessa área não são citados em conjunto com aqueles relacionados com os três tipos de empreendedorismo. De forma semelhante, isso demonstra uma baixa aderência entre os temas.

O mapa de palavras-chave, demonstrado na Figura 10, demonstra, assim como as representações anteriores, relativo distanciamento entre os temas de empreendedorismo e aqueles relacionados às finanças. As palavras-chave "finance" (abaixo), "crowdfunding" (esquerda) e "investment" (acima) estão mais distantes dos termos vinculados ao empreendedorismo do que palavras como "innovation" (acima), por exemplo. Destaca-se a proximidade do termo "financial performance" (esquerdo) com "sustainable entrepreneurship" (esquerdo), o que representa maior associação com essa palavra-chave do que com "social entrepreneurship" (centro), termo que recebeu a maior quantidade citações durante toda a pesquisa. 


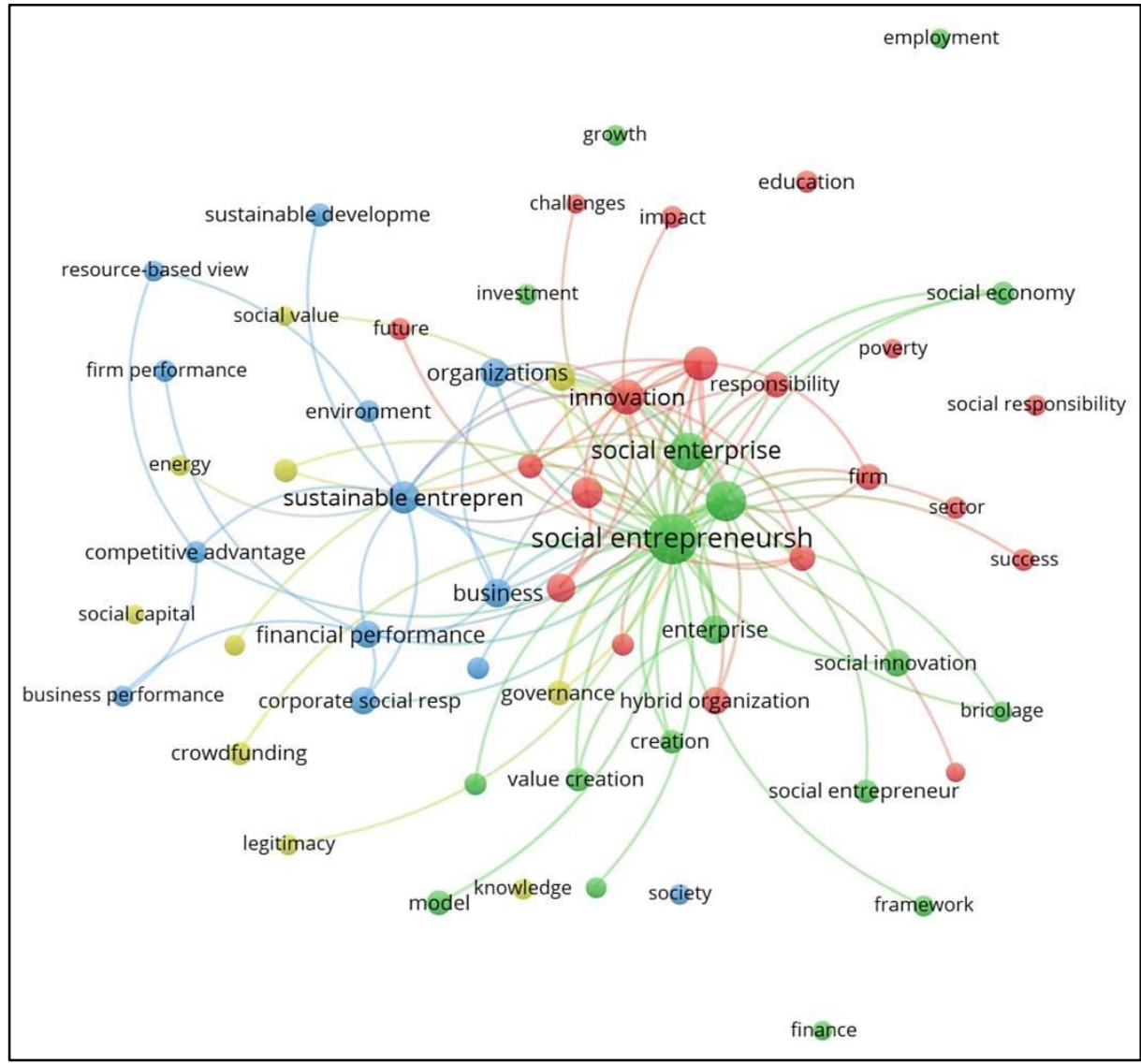

Figura 10 - Mapa de palavras-chave entre os três tipos de empreendedorismo e as finanças empresariais

Fonte: Elaborado pelos autores, 2020

Dentre os cinco artigos com maior quantidade de citações, ao contrário dos três casos tratados individualmente, não surgiram ocorrências com trabalhos relacionados às finanças, conforme demonstrado na Figura 11:

\begin{tabular}{|c|c|c|c|}
\hline Autor (ano) & Título & Periódico / Livro & $\begin{array}{l}\text { Quantidade } \\
\text { de citações }\end{array}$ \\
\hline $\begin{array}{l}\text { J. Mair, I. } \\
\text { Marti (2006) }\end{array}$ & $\begin{array}{l}\text { Social entrepreneurship research: A } \\
\text { source of explanation, prediction, and } \\
\text { delight }\end{array}$ & $\begin{array}{l}\text { Journal of World } \\
\text { Business }\end{array}$ & 1797 \\
\hline $\begin{array}{l}\text { JC Short et al. } \\
\text { (2009) }\end{array}$ & $\begin{array}{l}\text { Research in social entrepreneurship: } \\
\text { past contributions and future } \\
\text { opportunities }\end{array}$ & $\begin{array}{l}\text { Strategic } \\
\text { Entrepreneurship } \\
\text { Journal }\end{array}$ & 352 \\
\hline $\begin{array}{l}\text { A Fowler } \\
\text { (2000) }\end{array}$ & $\begin{array}{l}\text { NGDOs as a moment in history: beyond } \\
\text { aid to social entrepreneurship or civic } \\
\text { innovation? }\end{array}$ & $\begin{array}{l}\text { Third World } \\
\text { Quarterly }\end{array}$ & 309 \\
\hline $\begin{array}{l}\text { A Nicholls } \\
\text { (2009) }\end{array}$ & $\begin{array}{l}\text { 'We do good things, don't we?': } \\
\text { 'Blended Value Accounting' in social } \\
\text { entrepreneurship }\end{array}$ & $\begin{array}{l}\text { Accounting } \\
\text { Organizations and } \\
\text { Society }\end{array}$ & 261 \\
\hline $\begin{array}{l}\text { W Drayton } \\
(2002)\end{array}$ & $\begin{array}{l}\text { The citizen sector: Becoming as } \\
\text { entrepreneurial and competitive as } \\
\text { business }\end{array}$ & $\begin{array}{l}\text { California } \\
\text { Management } \\
\text { Review }\end{array}$ & 260 \\
\hline
\end{tabular}

Figura 11 - Trabalhos mais citados: três tipos de empreendedorismo e finanças empresariais Fonte: Elaborado pelos autores, 2020

\section{CONCLUSÕES}


A análise das relações entre o empreendedorismo social, sustentável e ambiental em conjunto com finanças empresariais, por meio do método bibliométrico, foi possível inicialmente apenas por mapas de palavras-chave e não demonstrou variedade nos trabalhos pesquisados, principalmente quanto ao empreendedorismo sustentável e ambiental.

Vale destacar que essas duas categorias não apresentaram grande discriminação nos mapas bibliométricos e resultaram em pequenas quantidades de referências relacionadas com finanças (79 e 51 trabalhos, respectivamente). Assim, torna-se difícil a análise individual dos mapas bibliométricos e das principais referências das duas áreas. A repetição dos artigos que surgem a partir das pesquisas gera uma "área cinzenta", o que impossibilita de identificar se um trabalho específico é relacionado ao empreendedorismo sustentável ou ambiental.

$\mathrm{Na}$ análise das relações desses tipos de empreendedorismo com as finanças, a seleção dos cinco trabalhos mais citados de cada área demonstra que $20 \%$ deles estavam associados com aspectos financeiros. Esse percentual é compatível o cruzamento dos totais de artigos que tratam dos três tipos de empreendedorismo com aqueles relacionados às finanças empresariais, conforme valores demonstrados na Tabela 1.

Quanto às palavras-chave de finanças empresariais, as mais relacionadas com os três tipos de empreendedorismo foram "crowdfunding" e "financial performance". O primeiro termo destaca-se por estar enquadrado em uma nova modalidade de financiamento coletivo, não restrito ao campo do empreendedorismo.

A relevância do termo crowdfunding pode estar associada com a identificação dos valores percebidos pelos financiadores nos objetivos das empresas que solicitaram os financiamentos, tema explorado na literatura por Calic; Mosakowski (2016), Bernardino; Santos (2016) e Lehner (2013). Porém, o desconhecimento dessa modalidade pelos empreendedores, conforme destacado por Bergamini; Navarro; Hilliard (2017), dificulta o sucesso na obtenção de recursos financeiros para os três tipos de empreendedorismo.

O estudo verificou que, apesar da proeminente preocupação com os campos social, sustentável e ambiental, os estudos sobre empreendedorismo carecem análises que expliquem as relações com as finanças empresariais. Seja por meio de empresas-âncora, crowdfunding ou outros mecanismos, a obtenção de capital também é um elemento necessário a essas iniciativas. Dessa forma, não apenas os aspectos financeiros, mas outros aspectos gerenciais devem ser explorados por pesquisas semelhantes. por meio de mapas bibliométricos. Apesar de, esses três tipos de empreendedorismo visarem objetivos além do lucro contábil e da riqueza econômica, estes são necessários para o funcionamento dos negócios.

Dessa forma, procurou-se reduzir essa lacuna teórica ao analisar de forma conjunta os aspectos financeiros na pesquisa sobre empreendedorismo social, sustentável e ambiental. De forma prática, verificaram-se os problemas ligados às finanças empresariais nesses três campos de empreendedorismo. Assim, não se reduziu as preocupações genuínas desses campos, porém, questões financeiras e de funding podem afetar os objetivos e o andamento de iniciativas nesses campos.

Como trabalhos futuros, recomenda-se as revisões de literatura que aprofundem os aspectos financeiros nos artigos relacionados aos três tipos de empreendedorismo identificados. Pesquisas bibliométricas em bases de dados diferentes daquelas já utilizadas no presente artigo também são fonte de potenciais trabalhos uma vez que possibilitam maior cobertura da literatura produzida sobre o tema. 


\section{REFERÊNCIAS}

ACHLEITNER, A.-K.; SPIESS-KNAFL, W.; VOLK, S. The financing structure of social enterprises: Conflicts and implications. International Journal of Entrepreneurial Venturing, v. 6, n. 1, p. 85-99, 2014.

BERGAMINI, T. P.; NAVARRO, C. L.-C.; HILLIARD, I. Is crowdfunding an appropriate financial model for social entrepreneurship? Academy of Entrepreneurship Journal, v. 23, n. 1, p. 44-57, 2017.

BERNARDINO, S.; SANTOS, J. F. Financing social ventures by crowdfunding: The influence of entrepreneurs' personality traits. International Journal of Entrepreneurship and Innovation, v. 17, n. 3, p. 173-183, 2016.

BOCKEN, N. M. P. Sustainable venture capital - Catalyst for sustainable start-up success? Journal of Cleaner Production, v. 108, p. 647-658, 2015.

BRANDSTETTER, L.; LEHNER, O. M. Opening the market for impact investments: The need for adapted portfolio tools. Entrepreneurship Research Journal, v. 5, n. 2, p. 87$107,2015$.

BROWN, T. E.; BOON, E.; PITT, L. F. Seeking funding in order to sell: Crowdfunding as a marketing tool. Business Horizons, v. 60, n. 2, p. 189-195, 2017.

CALIC, G.; MOSAKOWSKI, E. Kicking Off Social Entrepreneurship: How A Sustainability Orientation Influences Crowdfunding Success. Journal of Management Studies, v. 53, n. 5, p. 738-767, 2016.

CHEN, J. et al. Mechanism and policy combination of technical sustainable entrepreneurship crowdfunding in China: A system dynamics analysis. Journal of Cleaner Production, v. 177, p. 610-620, 2018.

CUMMING, D.; HENRIQUES, I.; SADORSKY, P. “Cleantech” venture capital around the world. International Review of Financial Analysis, v. 44, p. 86-97, 2016.

DACIN, P. A.; DACIN, M. T.; MATEAR, M. Social Entrepreneurship : Why We Don ' t Need a New Theory and How We Move Forward From Here. Academy of Management Perspectives, v. 24, n. 3, p. 37-58, 2010.

DEAN, T. J.; MCMULLEN, J. S. Toward a theory of sustainable entrepreneurship: Reducing environmental degradation through entrepreneurial action. Journal of Business Venturing, v. 22, n. 1, p. 50-76, 2007.

DEMIREL, P. et al. Born to be green: new insights into the economics and management of green entrepreneurshipSmall Business EconomicsUniversity of Southampton, Highfield Campus, Southampton, SO17 1BJ, United KingdomSpringer New York LLC, , 2017. Disponível em: <https://www.scopus.com/inward/record.uri?eid=2-s2.0$85030552534 \&$ doi $=10.1007 \% 2 F s 11187-017-9933-$

z\&partnerID=40\&md5=2ffda5c64f5c750a6b0037b91c5d96c3>

DJUPDAL, K. Decoupling environmental certification programmes from core operations: Firm performance reported by small and medium sized enterprises. World Review of Entrepreneurship, Management and Sustainable Development, v. 10, n. 4, p. 484-501, 2014.

ESTAPÉ-DUBREUIL, G.; ASHTA, A.; HÉDOU, J.-P. Micro-equity for sustainable development: Selection, monitoring and exit strategies of micro-angels. Ecological Economics, v. 130, p. 117-129, 2016.

GIBBS, D. Sustainability Entrepreneurs, Ecopreneurs and the Development of a Sustainable Economy. Greener Management International, n. 55, p. 63-79, 2009.

GUTIÉRREZ-SALCEDO, M. et al. Some bibliometric procedures for analyzing and evaluating research fields. Applied Intelligence, v. 48, n. 5, p. 1275-1287, 2018.

HALL, J. K.; DANEKE, G. A.; LENOX, M. J. Sustainable development and 
entrepreneurship: Past contributions and future directions. Journal of Business Venturing, v. 25, n. 5, p. 439-448, 2010.

HARJULA, L. Tensions between venture capitalists' and business-social entrepreneurs' goals: Will bottom-of-the-pyramid strategies offer a solution? Greener Management International, v. 2005, n. 51, p. 79-87, 2005.

HOOGENDOORN, B.; VAN DER ZWAN, P.; THURIK, R. Sustainable Entrepreneurship: The Role of Perceived Barriers and Risk. Journal of Business Ethics, v. 144, n. 2, p. 1-22, 2017.

HÖRISCH, J. Crowdfunding for environmental ventures: An empirical analysis of the influence of environmental orientation on the success of crowdfunding initiatives. Journal of Cleaner Production, v. 107, p. 636-645, 2015.

HÖRISCH, J. "Think big" or "small is beautiful"? An empirical analysis of characteristics and determinants of success of sustainable crowdfunding projects. International Journal of Entrepreneurial Venturing, v. 10, n. 1, p. 111-129, 2018.

KALLAB, T. E.; SALLOUM, C. Educational Attainment, Financial Support and Job Creation across Lebanese Social Entrepreneurships. Entrepreneurship Research Journal, v. 9, n. 1, p. 1-12, 2017.

KIRKWOOD, J.; WALTON, S. What motivates ecopreneurs to start businesses? International Journal of Entrepreneurial Behaviour and Research, v. 16, n. 3, p. 204$228,2010$.

KLEWITZ, J.; HANSEN, E. G. Sustainability-oriented innovation of SMEs: A systematic review. Journal of Cleaner Production, v. 65, p. 57-75, 2014.

KOELLNER, T.; SELL, J.; NAVARRO, G. Why and how much are firms willing to invest in ecosystem services from tropical forests? A comparison of international and Costa Rican firms. Ecological Economics, v. 69, n. 11, p. 2127-2139, 2010.

KRAUS, S. et al. Sustainable entrepreneurship orientation: A reflection on status-quo research on factors facilitating responsible managerial practices. Sustainability (Switzerland), v. 10, n. 2, 2018.

LANGE, D. E. DE. Start-up sustainability: An insurmountable cost or a life-giving investment? Journal of Cleaner Production, v. 156, p. 838-854, 2017.

LEHNER, O. M. Crowdfunding social ventures: a model and research agenda. Venture Capital, v. 15, n. 4, p. 289-311, 2013.

MAIR, J.; MARTÍ, I. Social entrepreneurship research: A source of explanation, prediction, and delight. Journal of World Business, v. 41, n. 1, p. 36-44, 2006.

MARTIN, M. Building impact businesses through hybrid financing. Entrepreneurship Research Journal, v. 5, n. 2, p. 109-126, 2015.

MILLER, T. L.; WESLEY, C. L. Assessing mission and resources for social change: An organizational identity perspective on social venture capitalists' decision criteria. Entrepreneurship: Theory and Practice, v. 34, n. 4, p. 705-733, 2010.

MRKAJIC, B.; MURTINU, S.; SCALERA, V. G. Is green the new gold? Venture capital and green entrepreneurship. Small Business Economics, v. 48, n. 2, p. 1-22, 2017.

NICHOLLS, A. "We do good things, don't we?": "Blended Value Accounting" in social entrepreneurship. Accounting, Organizations and Society, v. 34, n. 6-7, p. 755-769, 2009.

NICHOLLS, A. The institutionalization of social investment: The interplay of investment logics and investor rationalities. Journal of Social Entrepreneurship, v. 1, n. 1, p. 70-100, 2010.

OSAREH, F. Bibliometrics, Citation Analysis and Co-Citation Analysis: Libri, v. 46, p. 149-158, 1996.

RANDJELOVIC, J.; O'ROURKE, A. R.; ORSATO, R. J. The emergence of green 
venture capital. Business Strategy and the Environment, v. 12, n. 4, p. 240-253, 2003.

SCHUMPETER, J. A. The Theory of Economic Development: An inquiry into profits, capital, credit, interest, and the business cycle. New Jersey: Transaction Publishers, 1983.

SHANE, S.; VENKATARAMAN, S. The promise of entrepreneurship as a field of research. The Academy of Management Review, v. 25, n. 1, p. 217-226, 2000.

SIEGNER, M.; PINKSE, J.; PANWAR, R. Managing tensions in a social enterprise: The complex balancing act to deliver a multi-faceted but coherent social mission. Journal of Cleaner Production, v. 174, p. 1314-1324, 2018.

SIQUEIRA, A. C. O. et al. A longitudinal comparison of capital structure between young for-profit social and commercial enterprises. Journal of Business Venturing, v. 33, n. 2, p. 225-240, 2018.

VAN ECK, N. J.; WALTMAN, L. Software survey: VOSviewer, a computer program for bibliometric mapping. Scientometrics, v. 84, n. 2, p. 523-538, 2010.

WHEELER, D. et al. Creating sustainable local enterprise networks. MIT Sloan Management Review, v. 47, n. 1, p. 33-40, 2005.

ZUPIC, I.; ČATER, T. Bibliometric Methods in Management and Organization. Organizational Research Methods, v. 18, n. 3, p. 429-472, 2015. 